\title{
Convergence Theorems for Right Bregman Strongly Nonexpansive Mappings in Reflexive Banach Spaces
}

\author{
H. Zegeye ${ }^{1}$ and N. Shahzad ${ }^{2}$ \\ ${ }^{1}$ Department of Mathematics, University of Botswana, Private, Bag 00704, Gaborone, Botswana \\ ${ }^{2}$ Department of Mathematics, King Abdulaziz University, P.O. Box 80203, Jeddah 21589, Saudi Arabia
}

Correspondence should be addressed to N. Shahzad; nshahzad@kau.edu.sa

Received 21 February 2014; Accepted 7 May 2014; Published 27 May 2014

Academic Editor: Rudong Chen

Copyright (c) $2014 \mathrm{H}$. Zegeye and N. Shahzad. This is an open access article distributed under the Creative Commons Attribution License, which permits unrestricted use, distribution, and reproduction in any medium, provided the original work is properly cited.

We prove a strong convergence theorem for a common fixed point of a finite family of right Bregman strongly nonexpansive mappings in the framework of real reflexive Banach spaces. Furthermore, we apply our method to approximate a common zero of a finite family of maximal monotone mappings and a solution of a finite family of convex feasibility problems in reflexive real Banach spaces. Our theorems complement some recent results that have been proved for this important class of nonlinear mappings.

\section{Introduction}

In this paper, without other specifications, let $E$ be a real reflexive Banach space and $E^{*}$ as its dual, let $\mathbb{R}$ be the set of real numbers, and let $C$ be a nonempty, closed, and convex subset $E$. Let $f: E \rightarrow(-\infty, \infty]$ be a proper convex and lower semicontinuous function. Denote the domain of $f$ by $\operatorname{dom} f$; that is, $\operatorname{dom} f=\{x \in E: f(x)<\infty\}$. The Fenchel conjugate of $f$ is the function $f^{*}: E^{*} \rightarrow(-\infty,+\infty]$ defined by $f^{*}(y)=\sup \{\langle y, x\rangle-f(x): x \in E\} . f$ is called cofinite if $\operatorname{dom} f^{*}=E^{*}$. For any $x \in \operatorname{int}(\operatorname{dom} f)$ and $y \in E$, the righthand derivative of $f$ at $x$ in the direction of $y$ is defined by $f^{0}(x, y):=\lim _{t \rightarrow 0^{+}}(f(x+t y)-f(x)) / t$.

The function $f$ is called Gâteaux differentiable at $x$ if $\lim _{t \rightarrow 0^{+}}(f(x+t y)-f(x)) / t$ exists for any $y$. In this case, $f^{0}(x, y)$ coincides with $\nabla f(x)$, the value of the gradient $\nabla f$ of $f$ at $x$. The function $f$ is called Gâteaux differentiable if it is Gâteaux differentiable for any $x \in \operatorname{int}(\operatorname{dom} f)$. The function $f$ is said to be Fréchet differentiable at $x$ if this limit is attained uniformly in $\|y\|=1$ and $f$ is said to be uniformly Fréchet differentiable on a subset $C$ of $E$ if the limit is attained uniformly for $x \in C$ and $\|y\|=1$.

The function $f$ is said to be bounded if it maps bounded subsets of $E$ into bounded sets. We note that if $f: E \rightarrow$ $\mathbb{R}$ is uniformly Fréchet differentiable and bounded, then $\nabla f$ is uniformly continuous on bounded subsets of $E$ from the strong topology of $E$ to the strong topology of $E^{*}$ (Proposition 2.1, [1]) and $f^{*}$ is uniformly Fréchet on bounded subsets of $E^{*}$ (see [2]) and hence $\nabla f^{*}$ is uniformly continuous on bounded subsets of $E^{*}$ from the strong topology of $E^{*}$ to the strong topology of $E$.

Let $f: E \rightarrow(-\infty,+\infty]$ be a Gâteaux differentiable function. The function $D_{f}: \operatorname{dom} f \times \operatorname{int}(\operatorname{dom} f) \rightarrow[0,+\infty)$ defined by

$$
D_{f}(x, y):=f(x)-f(y)-\langle\nabla f(y), x-y\rangle
$$

is called the Bregman distance with respect to $f$ [3]

A Bregman projection [4] of $x \in \operatorname{int}(\operatorname{dom} f)$ onto the nonempty closed and convex set $C \subset \operatorname{int}(\operatorname{dom} f)$ is the unique vector $P_{C}^{f}(x) \in C$ satisfying

$$
D_{f}\left(P_{C}^{f}(x), x\right)=\inf \left\{D_{f}(y, x): y \in C\right\} .
$$

Remark 1. If $E$ is a smooth and strictly convex Banach space and $f(x)=\|x\|^{2}$ for all $x \in E$, then we have that $\nabla f(x)=2 J x$ for all $x \in E$, where $J$ is the normalized duality mapping from $E$ into $2^{E^{*}}$, and hence

(i) $D_{f}(x, y)$ reduces to $\phi(x, y)=\|x\|^{2}-2\langle x, J y\rangle+\|y\|^{2}$, for all $x, y \in E$, which is the Lyapunov function introduced by Alber [5] and 
(ii) $P_{C}^{f}(x)$ reduces to the generalized projection $\Pi_{C}(x)$ (see, e.g., [5]) which is defined by

$$
\phi\left(\Pi_{C}(x), x\right)=\min _{y \in C} \phi(y, x) .
$$

If $E=H$, a Hilbert space, $J$ is the identity mapping and hence the Bregman distance becomes $D_{f}(x, y)=\|x-y\|^{2}$, for $x, y \in H$, and the Bregman projection $P_{C}^{f}(x)$ reduces to the metric projection of $H$ onto $C, P_{C}(x)$.

Let $T: C \rightarrow C$ be a nonlinear mapping. Denote by $F(T)=\{x \in C: T x=x\}$ the set of fixed points of $T$. A mapping $T$ is said to be nonexpansive if $\|T x-T y\| \leq$ $\|x-y\|$, for all $x, y \in C$, and $T$ is called quasinonexpansive if $\|T x-p\| \leq\|x-p\|$, for all $x \in C$ and $p \in F(T)$. A point $p \in C$ is called an asymptotic fixed point of $T$ (see [6]) if $C$ contains a sequence $\left\{x_{n}\right\}$ which converges weakly to $p$ such that $\lim _{n \rightarrow \infty}\left\|x_{n}-T x_{n}\right\|=0$. We denote by $\widehat{F}(T)$ the set of asymptotic fixed points of $T$.

A mapping $T: C \rightarrow \operatorname{int}(\operatorname{dom} f)$ is called

(i) left quasi-Bregman nonexpansive [7] if $F(T) \neq \emptyset$ and

$$
D_{f}(p, T x) \leq D_{f}(p, x), \quad \forall x \in C, p \in F(T) ;
$$

(ii) left Bregman relatively nonexpansive [7] if $F(T) \neq \emptyset$ and

$$
D_{f}(p, T x) \leq D_{f}(p, x)
$$$$
\forall x \in C, p \in F(T), \widehat{F}(T)=F(T) ;
$$

(iii) left Bregman strongly nonexpansive (see $[8,9]$ ), with respect to nonempty $\widehat{F}(T)$, if

$D_{f}(p, T x) \leq D_{f}(p, x), \quad \forall x \in C, p \in \widehat{F}(T) ;$

and, if, whenever $\left\{x_{n}\right\} \subset C$ is bounded, $p \in \widehat{F}(T)$ and

$$
\lim _{n \rightarrow \infty}\left(D_{f}\left(p, x_{n}\right)-D_{f}\left(p, T x_{n}\right)\right)=0,
$$

it follows that

$$
\lim _{n \rightarrow \infty} D_{f}\left(T x_{n}, x_{n}\right)=0
$$

(iv) left Bregman firmly nonexpansive $[10]$ if $F(T) \neq \emptyset$ and for all $x, y \in C$,

$$
\begin{aligned}
& \langle\nabla f(T x)-\nabla f(T y), T x-T y\rangle \\
& \quad \leq\langle\nabla f(x)-\nabla f(y), T x-T y\rangle,
\end{aligned}
$$

or, equivalently,

$$
\begin{aligned}
& D_{f}(T x, T y)+D_{f}(T y, T x)+D_{f}(T x, x)+D_{f}(T y, y) \\
& \quad \leq D_{f}(T x, y)+D_{f}(T y, x) .
\end{aligned}
$$

If $T$ is left Bregman firmly nonexpansive and $f$ is Legendre function which is bounded, uniformly Fréchet differentiable, and totally convex on bounded subsets of $E$, then it is known in [10] that $F(T)=\widehat{F}(T)$ and $F(T)$ is closed and convex (see [10]). It follows that every left Bregman firmly nonexpansive mapping is Bregman strongly nonexpansive with respect to a nonempty set $F(T)=\widehat{F}(T)$.

Existence and approximation of fixed points of nonexpansive and quasinonexpansive mappings have been intensively studied for almost fifty years or so by various authors (see e.g., [11-24] and the references therein) in Hilbert spaces. But most of the methods failed to give the same conclusion in Banach spaces more general than Hilbert spaces. One of the reasons is that a nonexpansive mapping in Hilbert spaces may not be nonexpansive in Banach spaces (e.g., the resolvent $R_{A}=(I+A)^{-1}$ of a maximal monotone mapping $A: H \rightarrow$ $2^{H}$ and the metric projection $P_{K}$ onto a nonempty, closed, and convex subset $C$ of $H$ ).

To overcome this problem, researchers use the distance function $D_{f}(\cdot, \cdot)$ introduced by Bregman [4] instead of norm which opened a growing area of research in designing and analyzing iterative techniques for solving variational inequalities, approximating equilibria, computing fixed points of nonlinear mappings, and approximating solutions of convex feasibility problems (see, e.g., $[4,25-28]$ and the references therein).

In [29], Reich and Sabach proposed the following algorithm for finding a common fixed point of finitely many left Bregman firmly nonexpansive self-mappings $T_{i}(i=$ $1,2, \ldots, N)$ on $E$ satisfying $\cap_{i=1}^{N} F\left(T_{i}\right) \neq \emptyset$. For $x_{1} \in E$ let the sequence $\left\{x_{n}\right\}$ be defined by

$$
\begin{gathered}
Q_{0}^{i}=E, \\
y_{n}^{i}=T_{i}\left(x_{n}+e_{n}^{i}\right), \\
Q_{n+1}^{i}=\left\{z \in Q_{n}^{i}:\left\langle\nabla f\left(x_{n}+e_{n}^{i}\right)-\nabla f\left(y_{n}^{i}\right), z-y_{n}^{i}\right\rangle \leq 0\right\}, \\
Q_{n}=\bigcap_{i=1}^{N} Q_{n}^{i}, \\
x_{n+1}=P_{Q_{n+1}}^{f}\left(x_{0}\right), \quad \forall n \geq 1 .
\end{gathered}
$$

They proved that, under some suitable conditions, the sequence $\left\{x_{n}\right\}$ generated by (11) converges strongly to a point in $\cap_{i=1}^{N} F\left(T_{i}\right)$ and applied it to the solution of convex feasibility and equilibrium problems.

Very recently, by using Bregman projection, Reich and Sabach [9] proposed an algorithm for finding a common fixed point of finitely many left Bregman strongly nonexpansive mappings $T_{i}: C \rightarrow C(i=1,2, \ldots, N)$ satisfying $\cap_{i=1}^{N} F\left(T_{i}\right) \neq \emptyset$ in a reflexive Banach space $E$ as follows:

$x_{0} \in E, \quad$ chosen arbitrarily,

$$
y_{n}^{i}=T_{i}\left(x_{n}+e_{n}^{i}\right)
$$

$$
C_{n}^{i}=\left\{z \in E: D_{f}\left(z, y_{n}^{i}\right) \leq D_{f}\left(z, x_{n}+e_{n}^{i}\right)\right\},
$$




$$
\begin{gathered}
C_{n}=\bigcap_{i=1}^{N} C_{n}^{i}, \\
Q_{n}^{i}=\left\{z \in E:\left\langle\nabla f\left(x_{0}\right)-\nabla f\left(x_{n}\right), z-x_{n}\right\rangle \leq 0\right\}, \\
x_{n+1}=P_{C_{n} \cap Q_{n}}^{f}\left(x_{0}\right), \quad \forall n \geq 0 .
\end{gathered}
$$

Under some suitable conditions, they proved that the sequence $\left\{x_{n}\right\}$ generated by (12) converges strongly to a point in $\cap_{i=1}^{N} F\left(T_{i}\right)$ and applied it to the solution of convex feasibility and equilibrium problems.

The above results naturally bring us to the following: $a$ natural question arises whether we can establish analogous results for right Bregman strongly nonexpansive mappings or not.

A mapping $T: C \rightarrow \operatorname{int}(\operatorname{dom} f)$ is called

(i) right quasi-Bregman nonexpansive [30] if $F(T) \neq \emptyset$ and

$$
D_{f}(T x, p) \leq D_{f}(x, p), \quad \forall x \in C, p \in F(T) ;
$$

(ii) right Bregman relatively nonexpansive [30] if $F(T) \neq \emptyset$ and

$$
\begin{array}{r}
D_{f}(T x, p) \leq D_{f}(x, p), \\
\forall x \in C, p \in F(T), \widehat{F}(T)=F(T) ;
\end{array}
$$

(iii) right Bregman strongly nonexpansive (see $[8,9]$ ), with respect to nonempty $\widehat{F}(T)$, if

$D_{f}(T x, p) \leq D_{f}(x, p), \quad \forall x \in C, p \in \widehat{F}(T) ;$

and if, whenever $\left\{x_{n}\right\} \subset C$ is bounded, $p \in \widehat{F}(T)$ and

$$
\lim _{n \rightarrow \infty}\left(D_{f}\left(x_{n}, p\right)-D_{f}\left(T x_{n}, p\right)\right)=0,
$$

it follows that

$$
\lim _{n \rightarrow \infty} D_{f}\left(x_{n}, T x_{n}\right)=0 ;
$$

(iv) right Bregman firmly nonexpansive [10] if $F(T) \neq \emptyset$ and for all $x, y \in C$,

$$
\begin{aligned}
& \langle\nabla f(T x)-\nabla f(T y), T x-T y\rangle \\
& \quad \leq\langle\nabla f(T x)-\nabla f(T y), x-y\rangle,
\end{aligned}
$$

or, equivalently,

$$
\begin{aligned}
& D_{f}(T x, T y)+D_{f}(T y, T x)+D_{f}(x, T x)+D_{f}(y, T y) \\
& \quad \leq D_{f}(x, T y)+D_{f}(y, T x) .
\end{aligned}
$$

Remark 2. It is shown in [10] that if $T$ is right Bregman firmly nonexpansive, then $\widehat{F}(T)=F(T)$ and hence it is right Bregman relatively nonexpansive mapping provided that the Legendre function $f$ is uniformly Fréchet differentiable and bounded on bounded sets of $E$.
The class of right Bregman firmly nonexpansive mappings associated with the Bregman distance induced by a convex function was introduced and studied by Martin-Marques et al. [30]. Examples of right Bregman firmly nonexpansive mappings are given in [30]. If $C$ is a nonempty and closed subset of $\operatorname{int}(\operatorname{dom} f)$, where $f$ is a Legendre and Fréchet differentiable function, and $T: C \rightarrow \operatorname{int}(\operatorname{dom} f)$ is a right Bregman strongly nonexpansive mapping, it is proved that $F(T)$ is closed (see [30]). In addition, they have shown that this class of mappings is closed under composition and convex combination and proved weak convergence of the Picard iterative method to a fixed point of a mapping under suitable conditions (see [31]). However, Picard iteration process has only weak convergence.

In this paper, it is our purpose to introduce an iterative scheme which converges strongly to a common fixed point of a finite family of right Bregman strongly nonexpansive mappings. As a consequence, we use our results to approximate a common zero of a finite family of maximal monotone mappings and a solution of a finite family of convex feasibility problems in reflexive real Banach spaces. Our results complements the recent results due to Reich and Sabach [9], Suantai et al. [32], and Zhang and Cheng [33] in the sense that our scheme is applicable for right Bregman strongly nonexpansive self-mappings on $C \subseteq E$.

\section{Preliminaries}

Let $f: E \rightarrow(-\infty,+\infty]$ be a convex and Gâteaux differentiable function. The modulus of total convexity of $f$ at $x \in \operatorname{dom} f$ is the function $v_{f}(x, \cdot):[0 ;+\infty) \rightarrow[0 ;+\infty]$ defined by

$$
v_{f}(x, t):=\inf \left\{D_{f}(y, x): y \in \operatorname{dom} f,\|y-x\|=t\right\} .
$$

The function $f$ is called totally convex at $x$ if $v_{f}(x, t)>0$, whenever $t>0$. The function $f$ is called totally convex if it is totally convex at any point $x \in \operatorname{int}(\operatorname{dom} f)$ and is said to be totally convex on bounded sets if $v_{f}(B, t)>0$ for any nonempty bounded subset $B$ of $E$ and $t>0$, where the modulus of total convexity of the function $f$ on the set $B$ is the function $v_{f}$ : $\operatorname{int}(\operatorname{dom} f) \times[0,+\infty) \rightarrow[0,+\infty]$ defined by

$$
v_{f}(B, t):=\inf \left\{V_{f}(x, t): x \in B \cap \operatorname{dom} f\right\} .
$$

We know that $f$ is totally convex on bounded sets if and only if $f$ is uniformly convex on bounded sets (see [27], Theorem 2.10).

The function $f$ is called essentially smooth, if $\partial f$ is both locally bounded and single-valued on its domain and it is called essentially strictly convex, if $(\partial f)^{-1}$ is locally bounded on its domain and $f$ is strictly convex on every convex subset of dom $\partial f . f$ is said to be Legendre, if it is both essentially smooth and essentially strictly convex. Since $E$ is reflexive, we know that $(\partial f)^{-1}=\partial f^{*}$ (see [34]), $f$ is essentially smooth if and only if $f^{*}$ is essentially strictly convex (see [35], Theorem 5.4), and $f$ is Legendre if and only if $f^{*}$ is Legendre (see [35], Corollary 5.5); if $f$ is Legendre, then $\nabla f$ is a bijection satisfying $\nabla f=\left(\nabla f^{*}\right)-1, \operatorname{ran} \nabla f=\operatorname{dom} \nabla f^{*}=\operatorname{int} \operatorname{dom} f^{*}$, 
and $\operatorname{ran} \nabla f^{*}=\operatorname{dom} f=\operatorname{int} \operatorname{dom} f$ (see [35], Theorem 5.10). From now on, we assume that the convex function $f: E \rightarrow$ $(-\infty,+\infty]$ is Legendre.

If $E$ is a smooth and strictly convex Banach space, then an important and interesting Legendre function is $f(x):=$ $(1 / p)\|x\|^{p}(1<p<\infty)$. In this case, the gradient $\nabla f$ of $f$ coincides with the generalized duality mapping of $E$; that is, $\nabla f=J_{p}(1<p<\infty)$. In particular, $\nabla f=I$, the identity mapping in Hilbert spaces.

In the sequel, we shall use the following lemmas.

Lemma 3 (see [31]). Let $f: E \rightarrow \mathbb{R}$ be a bounded, uniformly Fréchet differentiable, and totally convex on bounded subsets of $E$. For each $i=1, \ldots, N$, let $T_{i}: K \subset E \rightarrow K$ be a right Bregman strongly nonexpansive mapping with respect to $\widehat{F}\left(T_{i}\right)=F\left(T_{i}\right)$, and let $T:=T_{N} \circ T_{N-1} \circ \cdots \circ T_{1}$. If $\mathscr{F}:=$ $\cap_{i=1}^{N} F\left(T_{i}\right)$ is nonempty, then $T$ is also right Bregman strongly nonexpansive and $F(T)=\cap_{i=1}^{N} F\left(T_{i}\right)$.

Lemma 4 (see [30]). Let $f: E \rightarrow \mathbb{R}$ be a Fréchet differentiable function. Let $C$ be a nonempty closed convex subset of $\operatorname{int}(\operatorname{dom} f)$ and let $T: C \rightarrow \operatorname{int}(\operatorname{dom} f)$ be a right quasi-Bregman nonexpansive mapping. Then $F(T)$ is closed.

Lemma 5 (see [36]). The function $f: E \rightarrow(-\infty,+\infty)$ is totally convex on bounded subsets of $E$ if and only if for any two sequences $\left\{x_{n}\right\}$ and $\left\{y_{n}\right\}$ in $\operatorname{int}(\operatorname{dom} f)$ and $\operatorname{dom} f$, respectively, such that the first one is bounded and

$$
\lim _{n \rightarrow \infty} D_{f}\left(y_{n}, x_{n}\right)=0 \Longrightarrow \lim _{n \rightarrow \infty}\left\|y_{n}-x_{n}\right\|=0 \text {. }
$$

Lemma 6 (see [27]). Let $C$ be a nonempty, closed, and convex subset of $E$. Let $f: E \rightarrow \mathbb{R}$ be a Gâteaux differentiable and totally convex function and let $x \in E$. Then

(i) $z=P_{C}^{f}(x)$ if and only if $\langle\nabla f(x)-\nabla f(z), y-z\rangle \leq$ $0, \forall y \in C$;

(ii) $D_{f}\left(y, P_{C}^{f}(x)\right)+D_{f}\left(P_{C}^{f}(x), x\right) \leq D_{f}(y, x), \forall y \in C$.

Lemma 7 (see [37]). If $f: E \rightarrow(-\infty,+\infty]$ is a proper, lower semicontinuous, and convex function, then $f^{*}: E^{*} \rightarrow$ $(-\infty,+\infty]$ is a proper, weak ${ }^{*}$ lower semicontinuous and convex function. Thus, for all $z \in E$, we have

$$
D_{f}\left(z, \nabla f^{*}\left(\sum_{i=1}^{N} t_{i} \nabla f\left(x_{i}\right)\right)\right) \leq \sum_{i=1}^{N} t_{i} D_{f}\left(z, x_{i}\right) .
$$

Lemma 8 (see [31]). Let $f: E \rightarrow \mathbb{R}$ be admissible and totally bounded at a point $x \in \operatorname{int}(\operatorname{dom} f)$. Let $\left\{x_{n}\right\} \subset \operatorname{dom}(f)$. If $\left\{D_{f}\left(x_{n}, x\right)\right\}$ is bounded, then so is the sequence $\left\{x_{n}\right\}$.

Let $f: E \rightarrow \mathbb{R}$ be a Gâteaux differentiable function. Following [3,5], we make use of the function $V_{f}: E \times E^{*} \rightarrow$ $[0,+\infty)$ associated with $f$, which is defined by

$V_{f}\left(x, x^{*}\right)=f(x)-\left\langle x, x^{*}\right\rangle+f^{*}\left(x^{*}\right), \quad \forall x \in E, x^{*} \in E^{*}$.

Then, $V_{f}$ is nonnegative and

$$
V_{f}\left(x, x^{*}\right)=D_{f}\left(x, \nabla f^{*}\left(x^{*}\right)\right) \quad \forall x \in E, \quad x^{*} \in E^{*} .
$$

Moreover, by the subdifferential inequality,

$$
V_{f}\left(x, x^{*}\right)+\left\langle y^{*}, \nabla f^{*}\left(x^{*}\right)-x\right\rangle \leq V_{f}\left(x, x^{*}+y^{*}\right),
$$

for all $x \in E$ and $x^{*}, y^{*} \in E^{*}$ (see [38]).

Lemma 9 (see [39]). Let $\left\{a_{n}\right\}$ be a sequence of nonnegative real numbers satisfying the following relation:

$$
a_{n+1} \leq\left(1-\alpha_{n}\right) a_{n}+\alpha_{n} \delta_{n}, \quad n \geq n_{0},
$$

where $\left\{\alpha_{n}\right\} \subset(0,1)$ and $\left\{\delta_{n}\right\} \subset R$ satisfying the following conditions: $\lim _{n \rightarrow \infty} \alpha_{n}=0, \quad \sum_{n=1}^{\infty} \alpha_{n}=\infty$, and lim $\sup _{n \rightarrow \infty} \delta_{n} \leq 0$. Then, $\lim _{n \rightarrow \infty} a_{n}=0$.

Lemma 10 (see [40]). Let $\left\{a_{n}\right\}$ be sequences of real numbers such that there exists a subsequence $\left\{n_{i}\right\}$ of $\{n\}$ such that $a_{n_{i}}<$ $a_{n_{i}+1}$ for all $i \in \mathbb{N}$. Then there exists an increasing sequence $\left\{m_{k}\right\} \subset \mathbb{N}$ such that $m_{k} \rightarrow \infty$ and the following properties are satisfied by all (sufficiently large) numbers $k \in \mathbb{N}$ :

$$
a_{m_{k}} \leq a_{m_{k}+1}, \quad a_{k} \leq a_{m_{k}+1} .
$$

In fact, $m_{k}$ is the largest number $n$ in the set $\{1,2, \ldots, k\}$ such that the condition $a_{n} \leq a_{n+1}$ holds.

\section{Main Results}

Theorem 11. Let $f: E \rightarrow \mathbb{R}$ be a cofinite function which is bounded, uniformly Fréchet differentiable and totally convex on bounded subsets of $E$. Let $C$ be a nonempty, closed, and convex subset of $\operatorname{int}(\operatorname{dom} f)$ and let $T_{i}: C \rightarrow C$, for $i=1,2, \ldots, N$, be a finite family of right Bregman strongly nonexpansive mappings such that $F\left(T_{i}\right)=\widehat{F}\left(T_{i}\right)$, for each $i \in\{1,2, \ldots, N\}$. Assume that $\mathscr{F}:=\cap_{i=1}^{N} F\left(T_{i}\right)$ is nonempty. For $u, x_{1} \in C$, let $\left\{x_{n}\right\}$ be a sequence generated by

$$
x_{n+1}=\alpha_{n} u+\left(1-\alpha_{n}\right) T\left(x_{n}\right), \quad n=1,2, \ldots,
$$

where $T=T_{N} \circ T_{N-1} \circ \cdots \circ T_{1},\left\{\alpha_{n}\right\} \subset(0,1)$ satisfy $\lim _{n \rightarrow \infty} \alpha_{n}=$ 0 and $\sum_{n=1}^{\infty} \alpha_{n}=\infty$. Then, $\left\{x_{n}\right\}$ converges strongly to a point $p$ in $\mathscr{F}$.

Proof. Note that from Lemma 3 we have $\mathscr{F}=F(T)=$ $\cap_{i=1}^{N} F\left(T_{i}\right)$ and $T$ is right Bregman strongly nonexpansive mapping. Let $p \in \mathscr{F}$. Then, using (29), the convexity of $f$, and property of $T$ we get that

$$
\begin{aligned}
D_{f}\left(x_{n+1}, p\right) & =D_{f}\left(\alpha_{n} u+\left(1-\alpha_{n}\right) T x_{n}, p\right) \\
& \leq \alpha_{n} D_{f}(u, p)+\left(1-\alpha_{n}\right) D_{f}\left(T x_{n}, p\right) \\
& \leq \alpha_{n} D_{f}(u, p)+\left(1-\alpha_{n}\right) D_{f}\left(x_{n}, p\right) .
\end{aligned}
$$

Thus, by induction we obtain that

$$
D_{f}\left(x_{n+1}, p\right) \leq \max \left\{D_{f}(u, p), D_{f}\left(x_{1}, p\right)\right\} \quad \forall n \geq 1
$$

which implies that $\left\{D_{f}\left(x_{n}, p\right)\right\}$ and hence $D_{f}\left(T x_{n}, p\right)$ are bounded. Thus, from Lemma 8 we get that $\left\{x_{n}\right\}$ and $\left\{T x_{n}\right\}$ are 
bounded. Now, let $y_{n}=\nabla f\left(x_{n}\right)$. Then, iteration process (29) becomes

$$
\begin{array}{r}
y_{n+1}=\nabla f\left(\alpha_{n} \nabla f^{*}(\nabla f(u))+\left(1-\alpha_{n}\right) \nabla f^{*} T^{*}\left(y_{n}\right)\right), \\
n=1,2, \ldots,
\end{array}
$$

where $T^{*}:=\nabla f T \nabla f^{*}$, a conjugate of $T$. Since $\nabla f$ and $\nabla f^{*}$ are uniformly continuous on bounded subsets of int $(\operatorname{dom} f)$ and $\operatorname{int}\left(\operatorname{dom} f^{*}\right)$, respectively, we get that $\left\{y_{n}\right\}$ and $\left\{T^{*} y_{n}\right\}$ are bounded and by Section 6 of Martin-Marquez et al. [31] we have that $T^{*}$ is left Bergman strongly nonexpansive with respect to $\nabla f(F(T))$. In addition, by Proposition 3.3 of [30] we have that $\nabla f(F(T))=F\left(T^{*}\right)=\widehat{F\left(T^{*}\right)}:=\mathscr{F}^{\prime}$ is closed and convex. Let $p^{\prime}=P_{\mathscr{F}^{\prime}}^{f^{*}}(\nabla f(u))$. Now, from (32), (25), (26), and Lemma 6 we obtain that

$$
\begin{aligned}
& D_{f^{*}}\left(p^{\prime}, y_{n+1}\right) \\
&= D_{f^{*}}\left(p^{\prime}, \nabla f\left(\alpha_{n} \nabla f^{*}(\nabla f(u))+\left(1-\alpha_{n}\right) \nabla f^{*}\left(T^{*} y_{n}\right)\right)\right) \\
&= V_{f^{*}}\left(p^{\prime}, \alpha_{n} \nabla f^{*}(\nabla f(u))+\left(1-\alpha_{n}\right) \nabla f^{*}\left(T^{*} y_{n}\right)\right) \\
& \leq V_{f^{*}}\left(p^{\prime}, \alpha_{n} \nabla f^{*}(\nabla f(u))+\left(1-\alpha_{n}\right) \nabla f^{*}\left(T^{*} y_{n}\right)\right. \\
&\left.\quad-\alpha_{n}\left(\nabla f^{*}(\nabla f(u))-\nabla f^{*}\left(p^{\prime}\right)\right)\right) \\
&+\left\langle\alpha_{n}\left(\nabla f^{*}(\nabla f(u))-\nabla f^{*}\left(p^{\prime}\right)\right), y_{n+1}-p^{\prime}\right\rangle \\
&= V_{f^{*}}\left(p^{\prime}, \alpha_{n} \nabla f^{*}\left(p^{\prime}\right)+\left(1-\alpha_{n}\right) \nabla f^{*}\left(T^{*} y_{n}\right)\right) \\
&+\alpha_{n}\left\langle\nabla f^{*}(\nabla f(u))-\nabla f^{*}\left(p^{\prime}\right), y_{n+1}-p^{\prime}\right\rangle \\
& \leq \alpha_{n} V_{f^{*}}\left(p^{\prime}, \nabla f^{*}\left(p^{\prime}\right)\right)+\left(1-\alpha_{n}\right) V_{f^{*}}\left(p^{\prime}, \nabla f^{*}\left(T^{*} y_{n}\right)\right) \\
&+\alpha_{n}\left\langle\nabla f^{*}(\nabla f(u))-\nabla f^{*}\left(p^{\prime}\right), y_{n+1}-p^{\prime}\right\rangle \\
&=\left(1-\alpha_{n}\right) D_{f^{*}}\left(p^{\prime}, T^{*} y_{n}\right)+\alpha_{n}\left\langle\nabla f^{*}(\nabla f(u))\right. \\
& \leq \quad\left(1-\alpha_{n}\right) D_{f^{*}}\left(p^{\prime}, y_{n}\right)+\alpha_{n}\left\langle\nabla f^{*}(\nabla f(u))\right. \\
&\left.-\nabla f^{*}\left(p^{\prime}\right), y_{n+1}-p^{\prime}\right\rangle .
\end{aligned}
$$

Now, we consider two cases.

Case 1. Suppose that there exists $n_{0} \in \mathbb{N}$ such that $\left\{D_{f^{*}}\left(p^{\prime}, y_{n}\right)\right\}$ is decreasing for all $n \geq n_{0}$. Then, we get that $\left\{D_{f^{*}}\left(p^{\prime}, y_{n}\right)\right\}$ is convergent and hence

$$
D_{f^{*}}\left(p^{\prime}, y_{n}\right)-D_{f^{*}}\left(p^{\prime}, y_{n+1}\right) \longrightarrow 0 \quad \text { as } n \longrightarrow \infty \text {. }
$$

In addition, from (32) and Lemma 7 we have that

$$
\begin{aligned}
D_{f} & \left(p^{\prime}, y_{n+1}\right) \\
& =D_{f^{*}}\left(p^{\prime}, \nabla f\left(\alpha_{n} \nabla f^{*}(\nabla f(u))+\left(1-\alpha_{n}\right) \nabla f^{*}\left(T^{*} y_{n}\right)\right)\right) \\
& \leq \alpha_{n} D_{f^{*}}\left(p^{\prime}, \nabla f(u)\right)+\left(1-\alpha_{n}\right) D_{f^{*}}\left(p^{\prime}, T^{*} y_{n}\right) .
\end{aligned}
$$

Following from (35), (34), and the fact that $\alpha_{n} \rightarrow 0$, as $n \rightarrow$ $\infty$, we get that

$$
\begin{aligned}
D_{f^{*}} & \left(p^{\prime}, y_{n}\right)-D_{f^{*}}\left(p^{\prime}, T^{*} y_{n}\right) \\
= & D_{f^{*}}\left(p^{\prime}, y_{n}\right)-D_{f^{*}}\left(p^{\prime}, y_{n+1}\right) \\
& +D_{f^{*}}\left(p^{\prime}, y_{n+1}\right)-D_{f^{*}}\left(p^{\prime}, T^{*} y_{n}\right) \\
\leq & D_{f^{*}}\left(p^{\prime}, y_{n}\right)-D_{f^{*}}\left(p^{\prime}, y_{n+1}\right) \\
& +\alpha_{n}\left(D_{f^{*}}\left(p^{\prime}, u\right)-D_{f^{*}}\left(p^{\prime}, T^{*} y_{n}\right)\right) \longrightarrow 0 \\
& \text { as } n \longrightarrow \infty .
\end{aligned}
$$

This with the fact that $T^{*}$ is left Bregman strongly nonexpansive implies that

$$
\lim _{n \rightarrow \infty} D_{f^{*}}\left(T^{*} y_{n}, y_{n}\right)=0 .
$$

Then, by Lemma 5 we obtain that

$$
\lim _{n \rightarrow \infty}\left\|T^{*} y_{n}-y_{n}\right\|=0 .
$$

Now, since $E^{*}$ is reflexive and $\left\{y_{n+1}\right\}$ is bounded, there exists a subsequence $\left\{y_{n_{k}+1}\right\}$ of $\left\{y_{n+1}\right\}$ such that

$$
y_{n_{k}+1} \rightarrow y \in E^{*},
$$

$$
\begin{aligned}
& \limsup _{n \rightarrow \infty}\left\langle\nabla f^{*}(\nabla f(u))-\nabla f^{*}\left(p^{\prime}\right), y_{n+1}-p^{\prime}\right\rangle \\
& \quad=\limsup _{k \rightarrow \infty}\left\langle\nabla f^{*}(\nabla f(u))-\nabla f^{*}\left(p^{\prime}\right), y_{n_{k}+1}-p^{\prime}\right\rangle .
\end{aligned}
$$

Thus, from (39), (38), the fact that $T^{*}$ is left Bregman strongly nonexpansive mapping with $\widehat{F\left(T^{*}\right)}=F\left(T^{*}\right)$, and Lemma 6 we get that $y \in F\left(T^{*}\right)=\mathscr{F}^{\prime}$ and

$$
\begin{aligned}
& \limsup _{n \rightarrow \infty}\left\langle\nabla f^{*}(\nabla f(u))-\nabla f^{*}\left(p^{\prime}\right), y_{n+1}-p^{\prime}\right\rangle \\
& \quad=\limsup _{k \rightarrow \infty}\left\langle\nabla f^{*}(\nabla f(u))-\nabla f^{*}\left(p^{\prime}\right), y_{n_{k}+1}-p^{\prime}\right\rangle \\
& =\left\langle\nabla f^{*}(\nabla f(u))-\nabla f^{*}\left(p^{\prime}\right), y-p^{\prime}\right\rangle \leq 0 .
\end{aligned}
$$

Therefore, it follows from (33), (41), and Lemma 9 that $D_{f}\left(p^{\prime}, y_{n}\right) \rightarrow 0$ as $n \rightarrow \infty$. Consequently, by Lemma 5 we obtain that $y_{n} \rightarrow p^{\prime}=P_{\mathscr{F}^{\prime}}^{f^{*}}(\nabla f(u))$ and hence $x_{n}=$ $\nabla f^{*}\left(y_{n}\right) \rightarrow \nabla f^{*}\left(p^{\prime}\right)=p \in \mathscr{F}$.

Case 2. Suppose that there exists a subsequence $\left\{n_{i}\right\}$ of $\{n\}$ such that

$$
D_{f^{*}}\left(p^{\prime}, y_{n_{i}}\right)<D_{f^{*}}\left(p^{\prime}, y_{n_{i}+1}\right) \text {, }
$$


for all $i \in \mathbb{N}$. Then, by Lemma 10, there exist a nondecreasing sequence $\left\{m_{k}\right\} \subset \mathbb{N}$ such that $m_{k} \rightarrow \infty$ and

$$
\begin{aligned}
& D_{f^{*}}\left(p^{\prime}, y_{m_{k}}\right) \leq D_{f^{*}}\left(p^{\prime}, y_{m_{k}+1}\right), \\
& D_{f^{*}}\left(p^{\prime}, y_{k}\right) \leq D_{f^{*}}\left(p^{\prime}, y_{m_{k}+1}\right),
\end{aligned}
$$

for all $k \in \mathbb{N}$. Thus, we get that

$$
\begin{aligned}
D_{f^{*}} & \left(p^{\prime}, y_{m_{k}}\right)-D_{f^{*}}\left(p^{\prime}, T^{*} y_{m_{k}}\right) \\
\leq & D_{f^{*}}\left(p^{\prime}, y_{m_{k}}\right)-D_{f^{*}}\left(p^{\prime}, y_{m_{k}+1}\right) \\
& \quad+D_{f^{*}}\left(p^{\prime}, y_{m_{k}+1}\right)-D_{f^{*}}\left(p^{\prime}, T^{*} y_{m_{k}}\right) \\
\leq & D_{f^{*}}\left(p^{\prime}, y_{m_{k}}\right)-D_{f^{*}}\left(p^{\prime}, y_{m_{k}+1}\right) \\
& +\alpha_{m_{k}}\left(D_{f^{*}}\left(p^{\prime}, \nabla f(u)\right)-D_{f^{*}}\left(p^{\prime}, T^{*} y_{m_{k}}\right)\right) \rightarrow 0 .
\end{aligned}
$$

This implies that $D_{f^{*}}\left(T^{*} y_{n_{k}}, y_{n_{k}}\right) \rightarrow 0$ as $k \rightarrow \infty$. Now, following the method in Case 1 we obtain that

$$
\limsup _{k \rightarrow \infty}\left\langle\nabla f^{*}(\nabla f(u))-\nabla f^{*}\left(p^{\prime}\right), y_{m_{k}+1}-p^{\prime}\right\rangle \leq 0 .
$$

Now, from (33) we have that

$$
\begin{aligned}
D_{f^{*}} & \left(p^{\prime}, y_{m_{k}+1}\right) \\
\leq & \left(1-\alpha_{m_{k}}\right) D_{f^{*}}\left(p^{\prime}, y_{m_{k}}\right) \\
\quad & +\alpha_{m_{k}}\left\langle\nabla f^{*}(\nabla f(u))-\nabla f^{*}\left(p^{\prime}\right), y_{m_{k}+1}-p^{\prime}\right\rangle .
\end{aligned}
$$

But (43) and (46) imply that

$$
\begin{aligned}
\alpha_{m_{k}} D_{f^{*}}\left(p^{\prime}, y_{m_{k}}\right) & \\
\leq & D_{f^{*}}\left(p^{\prime}, y_{m_{k}}\right)-D_{f^{*}}\left(p^{\prime}, y_{m_{k}+1}\right) \\
& \quad+\alpha_{m_{k}}\left\langle\nabla f^{*}(\nabla f(u))-\nabla f^{*}\left(p^{\prime}\right), y_{m_{k}+1}-p^{\prime}\right\rangle \\
\leq & \alpha_{m_{k}}\left\langle\nabla f^{*}(\nabla f(u))-\nabla f^{*}\left(p^{\prime}\right), y_{m_{k}+1}-p^{\prime}\right\rangle,
\end{aligned}
$$

and noting that $\alpha_{m_{k}}>0$, we get that

$$
D_{f^{*}}\left(p^{\prime}, y_{m_{k}}\right) \leq\left\langle\nabla f^{*}(\nabla f(u))-\nabla f^{*}\left(p^{\prime}\right), y_{m_{k}+1}-p^{\prime}\right\rangle \text {. }
$$

Thus, using (45) we get that $D_{f^{*}}\left(p^{\prime}, y_{m_{k}}\right) \rightarrow 0$ and hence from (46) we have that $D_{f^{*}}\left(p^{\prime}, y_{m_{k}+1}\right) \rightarrow 0$ as $k \rightarrow \infty$. But $D_{f^{*}}\left(p^{\prime}, y_{k}\right) \leq D_{f^{*}}\left(p^{\prime}, y_{m_{k}+1}\right)$, for all $k \in \mathbb{N}$, implies that $D_{f^{*}}\left(p^{\prime}, y_{k}\right) \rightarrow 0$ and hence by Lemma 5 we obtain that $y_{k} \rightarrow p^{\prime}$ and $x_{k}=\nabla f^{*}\left(y_{k}\right) \rightarrow p=\nabla f^{*}\left(p^{\prime}\right) \epsilon$ $\mathscr{F}$. Therefore, from the above two cases, we can conclude that $\left\{x_{n}\right\}$ converges strongly to $p \in \mathscr{F}$ and the proof is complete.
Remark 12. We note that the sequence $\left\{x_{n}\right\}$ in Theorem 11 converges strongly to a point $p \in \mathscr{F}$ such that $p=\nabla f^{*}\left(p^{\prime}\right)$, where $p^{\prime}=P_{\mathscr{F}^{\prime}}(\nabla f(u))$.

If, in Theorem 11, we consider a single right Bregman strongly nonexpansive mapping, we get the following corollary.

Corollary 13. Let $E$ be a reflexive Banach space and let $f$ : $E \rightarrow \mathbb{R}$ be a cofinite function which is bounded, uniformly Fréchet differentiable, and totally convex on bounded subsets of $E$. Let $C$ be a nonempty, closed, and convex subset of $\operatorname{int}(\operatorname{dom} f$ ) and let $T: C \rightarrow C$ be a right Bregman strongly nonexpansive mapping such that $\widehat{F}(T)=F(T) \neq \emptyset$. For $u, x_{1} \in$ $C$ let $\left\{x_{n}\right\}$ be a sequence generated by

$$
x_{n+1}=\alpha_{n} u+\left(1-\alpha_{n}\right) T x_{n}, \quad n=1,2, \ldots,
$$

where $\left\{\alpha_{n}\right\} \subset(0,1)$ satisfy $\lim _{n \rightarrow \infty} \alpha_{n}=0$ and $\sum_{n=1}^{\infty} \alpha_{n}=\infty$. Then, $\left\{x_{n}\right\}$ converges strongly to some $p$ in $F(T)$.

If, in Theorem 11, we assume that each $T_{i},(i=$ $1,2, \ldots, N)$ is right Bregman firmly nonexpansive, then we have that $T=T_{N} \circ T_{N-1} \circ \cdots \circ T_{1}$ is right Bregman firmly nonexpansive with $\widehat{F}(T)=F(T)=\bigcap_{i=1}^{N} F\left(T_{i}\right)$ (see [10]) and hence it is right Bregman strongly nonexpansive mapping. Thus, we have the following.

Corollary 14. Let $f: E \rightarrow \mathbb{R}$ be a cofinite function which is bounded, uniformly Fréchet differentiable, and totally convex on bounded subsets of $E$. Let $C$ be a nonempty, closed, and convex subset of $\operatorname{int}(\operatorname{dom} f)$ and let $T_{i}: C \rightarrow C$, for $i=1,2, \ldots, N$, be a finite family of right Bregman firmly nonexpansive mappings with $\mathscr{F}:=\cap_{i=1}^{N} F\left(T_{i}\right) \neq \emptyset$. For $u, x_{1} \in$ $C$ let $\left\{x_{n}\right\}$ be a sequence generated by

$$
x_{n+1}=\alpha_{n} u+\left(1-\alpha_{n}\right) T x_{n}, \quad n=1,2, \ldots,
$$

where $T=T_{N} \circ T_{N-1} \circ \cdots \circ T_{1},\left\{\alpha_{n}\right\} \subset(0,1)$ satisfying $\lim _{n \rightarrow \infty} \alpha_{n}=0$ and $\sum_{n=1}^{\infty} \alpha_{n}=\infty$. Then, $\left\{x_{n}\right\}$ converges strongly to $p$ in $\mathscr{F}$.

\section{Applications}

4.1. Zeroes of Maximal Mappings. Let $A: E \rightarrow 2^{E^{*}}$ be a maximal monotone mapping. Recently, many authors studied zero points of monotone mappings using different methods (see e.g., [13, 25, 28, 30, 31, 38]). In this section we use Halpern's type scheme to find common zeros of a finite family of maximal monotone set-valued mappings.

Definition 15 (see [31]). Let $f: E \rightarrow(-\infty,+\infty]$ be an admissible function and let $A: E \rightarrow 2^{E^{*}}$ be a set-valued mapping such that $\operatorname{int}(\operatorname{dom} f) \cap \operatorname{dom} A \neq \emptyset$. The conjugate resolvent of $A$ with respect to $f$, or the conjugate $\nabla f$ resolvent, is the operator $\operatorname{CRes}_{A}^{f}: E^{*} \rightarrow 2^{E^{*}}$ defined by

$$
\operatorname{CRes}_{A}^{f}:=\left(I+A \circ \nabla f^{*}\right)^{-1} .
$$


Remark 16. If, in addition, $A$ is monotone and $f_{\operatorname{int}(\operatorname{dom} f)}$ is strictly convex, then it is shown in [31] that $\operatorname{CRes}_{A}^{f}$ is right Bregman firmly nonexpansive and $\nabla f^{*}\left(F\left(\operatorname{CRes}_{A}^{f}\right)\right)=$ $\operatorname{int}(\operatorname{dom} f) \cap A^{-1}\left(0^{*}\right)$. Moreover, we know that if $f$ is Legendre, bounded, and uniformly continuous on bounded subsets of $E$, then, for every right Bregman firmly nonexpansive operator $T, \widehat{F}(T)=F(T)$ (see [10]). Thus, under these assumptions on $A$ and $f$, the operator $\operatorname{CRes}_{A}^{f}$ is right Bregman strongly nonexpansive mapping.

We shall need the following lemma.

Lemma 17 (see [30]). Let $f: E \rightarrow \mathbb{R}$ be a strictly convex, cofinite, and admissible function, and let $A: E \rightarrow 2^{E^{*}}$ be a set-valued monotone mapping. Then $A$ is maximal monotone if and only if $\operatorname{dom}\left(\operatorname{CRes}_{A}^{f}\right)=E^{*}$.

Theorem 18. Let $f: E \rightarrow \mathbb{R}$ be a cofinite function such that $f^{*}$ is uniformly Fréchet differentiable and totally convex on bounded subsets of $E^{*}$. Let $A_{i}: E \rightarrow 2^{E^{*}}, i=1,2, \ldots, N$, be maximal monotone mappings such that $\mathscr{F}:=\cap_{i=1}^{N} A_{i}^{-1}\left(0^{*}\right) \neq \emptyset$. For each $w, z_{1} \in E^{*}$, consider the sequence $\left\{z_{n}\right\}$ generated iteratively by

$$
z_{n+1}=\alpha_{n} w+\left(1-\alpha_{n}\right) T\left(z_{n}\right), \quad n=1,2, \ldots,
$$

where $T=\operatorname{CRes}_{A_{N}}^{f} \circ \operatorname{CRes}_{N-1}^{f} \circ \cdots \circ \operatorname{CRes}_{A_{1}}^{f},\left\{\alpha_{n}\right\} \subset(0,1)$ satisfy $\lim _{n \rightarrow \infty} \alpha_{n}=0$, and $\sum_{n=1}^{\infty} \alpha_{n}=\infty$. Then, $\left\{z_{n}\right\}$ converges strongly to $p^{\prime}$ in $F(T)=\cap_{i=1}^{N} F\left(\operatorname{CRes}_{A_{i}}^{f}\right)$, and $\nabla f^{*}\left(p^{\prime}\right)=p \epsilon$ $\mathscr{F}$.

Proof. From Lemma 17 we know that each $T_{i}=\operatorname{CRes}_{A_{i}}^{f}, i=$ $1,2, \ldots, N$ is a mapping from $E^{*}$ into itself, since

$$
\bigcap_{i=1}^{N} F\left(\operatorname{CRes}_{A_{i}}^{f}\right)=\bigcap_{i=1}^{N} \nabla f\left(A_{i}^{-1}\left(0^{*}\right)\right)=\nabla f(\mathscr{F}) \neq \emptyset .
$$

Remark 16 guarantees that each $T_{i}, i=1,2, \ldots, N$ is right Bregman strongly nonexpansive mapping with respect to $F\left(T_{i}\right)=\widehat{F}\left(T_{i}\right)$. Now the result follows immediately from Theorem 11 applied to $E^{*}$.

4.2. Convex Feasibility Problems. The convex feasibility problem (CFP) is finding an element $x^{*} \in \cap_{i=1}^{N} K_{i}$, where $K_{i}$ for $i=1,2, \ldots, N$, are nonempty, closed, and convex subsets of $E$. Let $K \subset \operatorname{int}(\operatorname{dom} f)$. The right Bregman projection [30] onto $K$ is the operator $P_{K}^{f}: \operatorname{int}(\operatorname{dom} f) \rightarrow K$ defined by

$$
\begin{aligned}
& P_{K}^{f}(x):=\underset{y \in K}{\arg \lim }\left\{D_{f}(x, y)\right\} \\
& \quad=\left\{z \in K: D_{f}(x, z) \leq D_{f}(x, y) \forall y \in K\right\} .
\end{aligned}
$$

If $f: E \rightarrow \mathbb{R}$ is Legendre and uniformly continuous on bounded subsets of $E$ and $f$ is weakly sequentially continuous, then the right Bregman projection $P_{K_{i}}^{f}$ is right Bregman strongly nonexpansive mapping with $F\left(P_{K_{i}}^{f}\right)=\widehat{F}\left(P_{K_{i}}^{f}\right)$ (see [30]). Therefore, if we take $T_{i}=P_{K_{i}}^{f}$ for each $i \in\{1,2, \ldots, N\}$, then we get an algorithm for solving convex feasibility problems. More precisely, we have the following result.

Theorem 19. Let $f: E \rightarrow \mathbb{R}$ be a cofinite function which is bounded, uniformly continuous, and totally convex on bounded subsets of E. Assume that $\nabla f$ is weakly sequentially continuous. Let $K_{i}, i=1, \ldots, N$ be $N$ nonempty, closed, and convex subsets of $E$ such that $\mathscr{F}:=\cap_{i=1}^{N} K_{i} \neq \emptyset$. For each $x_{1} \in K$, let the sequence $\left\{x_{n}\right\}$ be generated iteratively by

$$
x_{n+1}=\alpha_{n} u+\left(1-\alpha_{n}\right) T\left(z_{n}\right), \quad n=1,2, \ldots,
$$

where $T=P_{K_{N}}^{f} \circ P_{K_{N-1}}^{f} \circ \cdots \circ P_{K_{1}}^{f},\left\{\alpha_{n}\right\} \subset(0,1)$ satisfy $\lim _{n \rightarrow \infty} \alpha_{n}=0$, and $\sum_{n=1}^{\infty} \alpha_{n}=\infty$. Then, $\left\{x_{n}\right\}$ converges strongly to $p$ in $\mathscr{F}$.

Remark 20. Theorem 11 complements the results due to Reich and Sabach [9], Suantai et al. [32], and Zhang and Cheng [33] in the sense that our scheme is applicable for right Bregman strongly nonexpansive self-mappings on $C$, where $C$ is nonempty, closed, and convex subset of $E$.

\section{Conflict of Interests}

The authors declare that they have no conflict of interests regarding the publication of this paper.

\section{Acknowledgments}

This paper was funded by the Deanship of Scientific Research (DSR), King Abdulaziz University, Jeddah. The second author acknowledges with thanks DSR for financial support.

\section{References}

[1] S. Reich and S. Sabach, "A strong convergence theorem for a proximal-type algorithm in reflexive Banach spaces," Journal of Nonlinear and Convex Analysis, vol. 10, no. 3, pp. 471-485, 2009.

[2] C. Zalinescu, Convex Analysis in General Vector Spaces, World Scientific, River Edge, NJ, USA, 2002.

[3] Y. Censor and A. Lent, "An iterative row-action method for interval convex programming," Journal of Optimization Theory and Applications, vol. 34, no. 3, pp. 321-353, 1981.

[4] L. M. Bregman, "The relaxation method for finding the common point of convex sets and its application to the solution of problems in convex programming," USSR Computational Mathematics and Mathematical Physics, vol. 7, no. 3, pp. 200217, 1967.

[5] Y. I. Alber, "Metric and generalized projection operators," in Banach Spaces: Properties and Applications, Lecture Notes in Pure and Applied Mathematics, pp. 15-50, 1996.

[6] S. Reich, "A weak convergence theorem for the alternating method with Bregman distances," in Theory and Applications of Nonlinear Operators of Accretive and Monotone Type, vol. 178 of Lecture Notes in Pure and Applied Mathematics, pp. 313-318, Marcel Dekker, New York, NY, USA, 1996. 
[7] S. Reich and S. Sabach, "Two strong convergence theorems for a proximal method in reflexive Banach spaces," Numerical Functional Analysis and Optimization, vol. 31, no. 1-3, pp. 2244, 2010.

[8] R. E. Bruck and S. Reich, "Nonexpansive projections and resolvents of accretive operators in Banach spaces," Houston Journal of Mathematics, vol. 3, no. 4, pp. 459-470, 1977.

[9] S. Reich and S. Sabach, "Two strong convergence theorems for Bregman strongly nonexpansive operators in reflexive Banach spaces," Nonlinear Analysis. Theory, Methods and Applications, vol. 73, no. 1, pp. 122-135, 2010.

[10] S. Reich and S. Sabach, "Existence and approximation of fixed points of Bregman firmly nonexpansive mappings in reflexive Banach spaces," in Fixed-point Algorithms for Inverse Problems in Science and Engineering, vol. 49, pp. 301-316, Springer, New York, NY, USA, 2011.

[11] F. E. Browder, "Convergence of approximants to fixed points of nonexpansive non-linear mappings in Banach spaces," Archive for Rational Mechanics and Analysis, vol. 24, no. 1, pp. 82-90, 1967.

[12] B. Halpern, "Fixed points of nonexpanding maps," Bulletin of the American Mathematical Society, vol. 73, pp. 957-961, 1967.

[13] S. Reich, "Strong convergence theorems for resolvents of accretive operators in Banach spaces," Journal of Mathematical Analysis and Applications, vol. 75, no. 1, pp. 287-292, 1980.

[14] N. Shahzad and A. Udomene, "Fixed point solutions of variational inequalities for asymptotically nonexpansive mappings in Banach spaces," Nonlinear Analysis: Theory, Methods and Applications, vol. 64, no. 3, pp. 558-567, 2006.

[15] H. Zegeye and N. Shahzad, "Strong convergence theorems for monotone mappings and relatively weak nonexpansive mappings," Nonlinear Analysis. Theory, Methods and Applications, vol. 70, no. 7, pp. 2707-2716, 2009.

[16] H. Zegeye and N. Shahzad, "Viscosity approximation methods for a common fixed point of finite family of nonexpansive mappings," Applied Mathematics and Computation, vol. 191, no. 1, pp. 155-163, 2007.

[17] H. Zegeye and N. Shahzad, "Approximation methods for a common fixed point of a finite family of nonexpansive mappings," Numerical Functional Analysis and Optimization, vol. 28, no. 1112, pp. 1405-1419, 2007.

[18] N. Shahzad and H. Zegeye, "Strong convergence of an implicit iteration process for a finite family of generalized asymptotically quasi-nonexpansive maps," Applied Mathematics and Computation, vol. 189, no. 2, pp. 1058-1065, 2007.

[19] H. Zegeye and N. Shahzad, "Viscosity methods of approximation for a common fixed point of a family of quasinonexpansive mappings," Nonlinear Analysis: Theory, Methods and Applications, vol. 68, no. 7, pp. 2005-2012, 2008.

[20] H. Zegeye and N. Shahzad, "Strong convergence theorems for a finite family of nonexpansive mappings and semigroups via the hybrid method," Nonlinear Analysis: Theory, Methods and Applications, vol. 72, no. 1, pp. 325-329, 2010.

[21] H. Zegeye, E. U. Ofoedu, and N. Shahzad, "Convergence theorems for equilibrium problem, variational inequality problem and countably infinite relatively quasi-nonexpansive mappings," Applied Mathematics and Computation, vol. 216, no. 12, pp. 3439-3449, 2010.

[22] H. Zegeye and N. Shahzad, "A hybrid approximation method for equilibrium, variational inequality and fixed point problems," Nonlinear Analysis: Hybrid Systems, vol. 4, no. 4, pp. 619-630, 2010.
[23] H. Zegeye, N. Shahzad, and M. A. Alghamdi, "Convergence of Ishikawa's iteration method for pseudocontractive mappings," Nonlinear Analysis: Theory, Methods and Applications, vol. 74, no. 18, pp. 7304-7311, 2011.

[24] H. Zegeye, N. Shahzad, and M. A. Alghamdi, "Minimumnorm fixed point of pseudocontractive mappings," Abstract and Applied Analysis, vol. 2012, Article ID 926017, 15 pages, 2012.

[25] H. H. Bauschke, J. M. Borwein, and P. L. Combettes, "Bregman monotone optimization algorithms," SIAM Journal on Control and Optimization, vol. 42, no. 2, pp. 596-636, 2003.

[26] H. H. Bauschke and J. M. Borwein, "Legendre functions and the method of random Bregman projections," Journal of Convex Analysis, vol. 4, no. 1, pp. 27-67, 1997.

[27] D. Butnariu and E. Resmerita, "Bregman distances, totally convex functions, and a method for solving operator equations in Banach spaces," Abstract and Applied Analysis, vol. 2006, Article ID 84919, 39 pages, 2006.

[28] N. N. Shahzad, H. Zegeye, and A. Alotaibi, "Convergence results for a common solution of a finite family of variational inequality problems for monotone mappings with Bregman distance," Fixed Point Theory and Applications, vol. 2013, 343 pages, 2013.

[29] S. Reich and S. Sabach, "A projection method for solving nonlinear problems in reflexive Banach spaces," Journal of Fixed Point Theory and Applications, vol. 9, no. 1, pp. 101-116, 2011.

[30] V. Martin-Marquez, S. Reich, and S. Sabach, "Right Bregman nonexpansive operators in Banach spaces," Nonlinear Analysis, vol. 75, no. 14, pp. 5448-5465, 2012.

[31] V. Martin-Marquez, S. Reich, and S. Sabach, "Bregman strongly nonexpansive operators in reflexive Banach spaces," Journal of Mathematical Analysis and Applications, vol. 400, no. 2, pp. 597614, 2013.

[32] S. Suantai, Y. J. Choc, and P. Cholamjiak, "Halpern's iteration for Bregman strongly nonexpansive mappings in reflexive Banach spaces," Computers and Mathematics with Applications, vol. 64, no. 4, pp. 489-499, 2012.

[33] Q. B. Zhang and C. Z. Cheng, "Strong convergence theorem for a family of Lipschitz pseudocontractive mappings in a Hilbert space," Mathematical and Computer Modelling, vol. 48, no. 3-4, pp. 480-485, 2008.

[34] J. F. Bonnans and A. Shapiro, Perturbation Analysis of Optimization Problems, Springer, New York, NY, USA, 2000.

[35] H. H. Bauschke, J. M. Borwein, and P. L. Combettes, "Essential smoothness, essential strict convexity, and Legendre functions in Banach spaces," Communications in Contemporary Mathematics, vol. 3, no. 4, pp. 615-647, 2001.

[36] D. Butnariu and A. N. Iusem, Totally Convex Functions for Fixed Points Computation and Infinite Dimensional Optimization, vol. 40, Kluwer Academic, Dodrecht, The Netherlands, 2000.

[37] R. R. Phelps, Convex Functions, Monotone Operators and Differentiability, vol. 1364 of Lecture Notes in Mathematics, Springer, Berlin, Germany, 2nd edition, 1993.

[38] F. Kohsaka and W. Takahashi, "Proximal point algorithms with Bregman functions in Banach spaces," Journal of Nonlinear and Convex Analysis, vol. 6, no. 3, pp. 505-523, 2005.

[39] H. K. Xu, "Another control condition in an iterative method for nonexpansive mappings," Bulletin of the Australian Mathematical Society, vol. 65, no. 1, pp. 109-113, 2002.

[40] P. E. Mainge, "Strong convergence of projected subgradient methods for nonsmooth and nonstrictly convex minimization," Set-Valued Analysis, vol. 16, no. 7-8, pp. 899-912, 2008. 


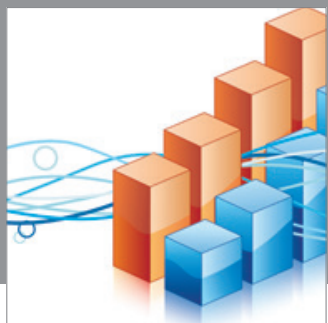

Advances in

Operations Research

mansans

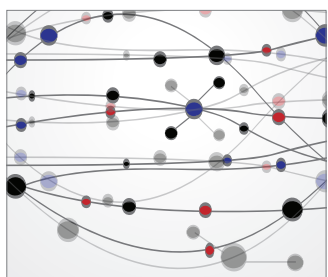

The Scientific World Journal
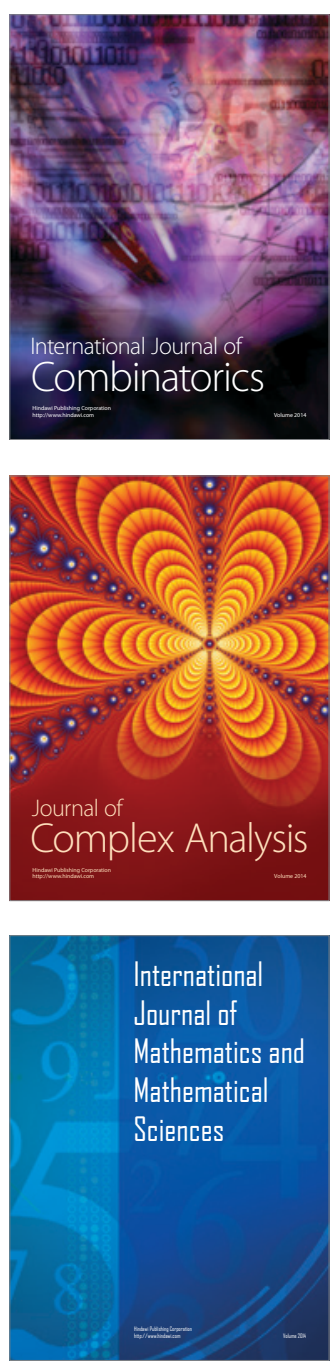
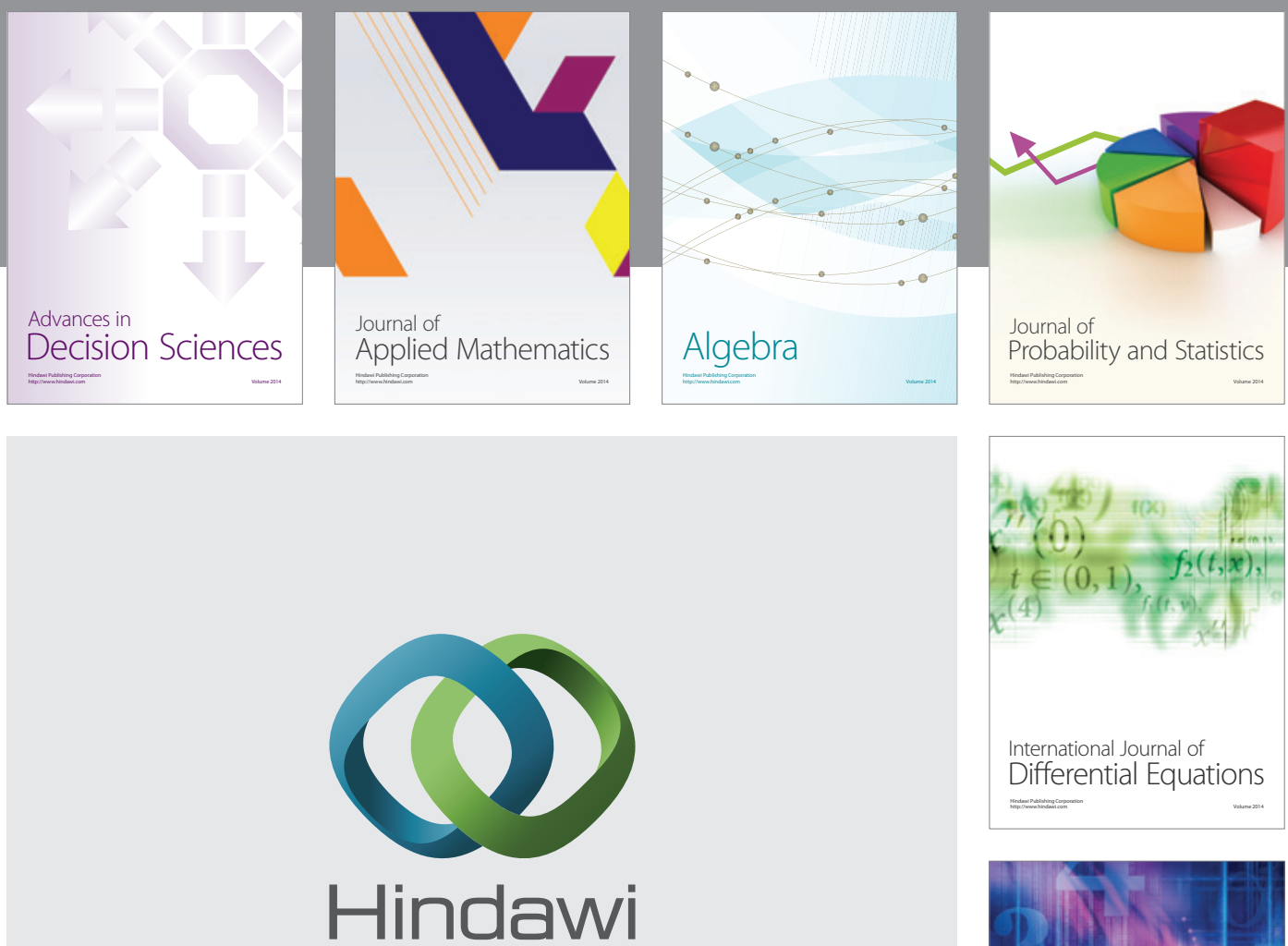

Submit your manuscripts at http://www.hindawi.com
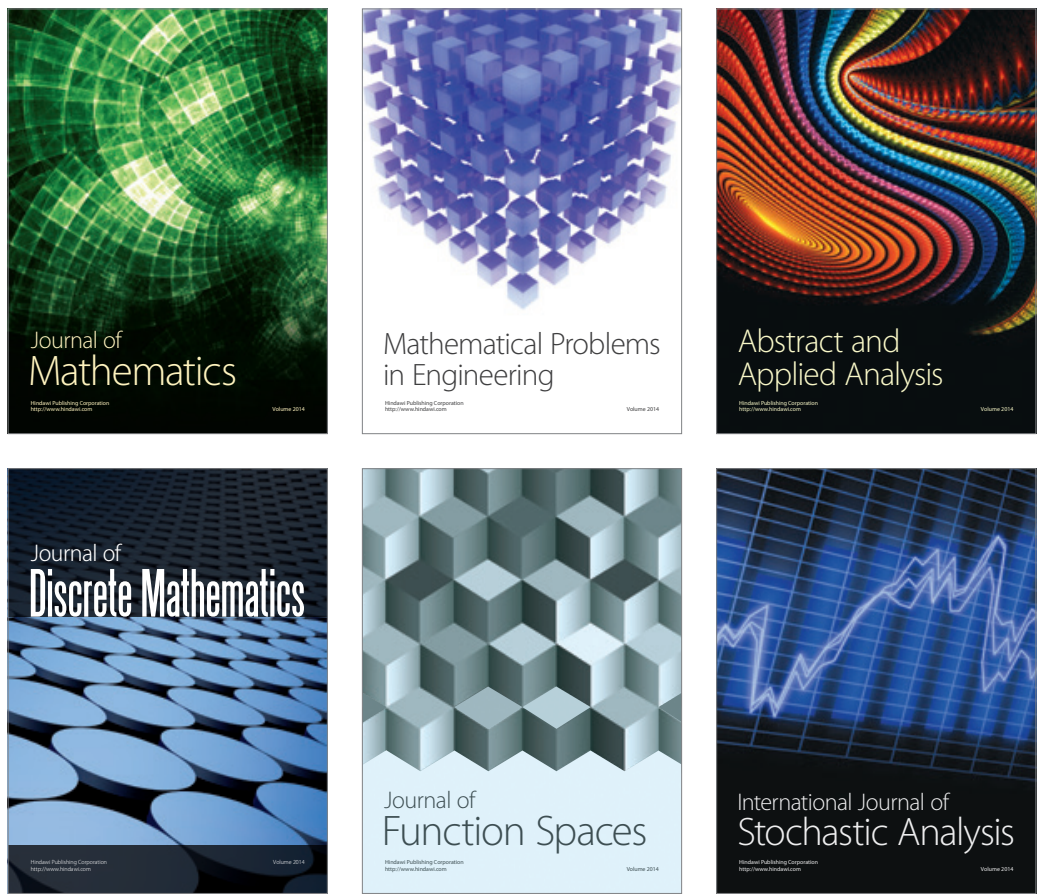

Journal of

Function Spaces

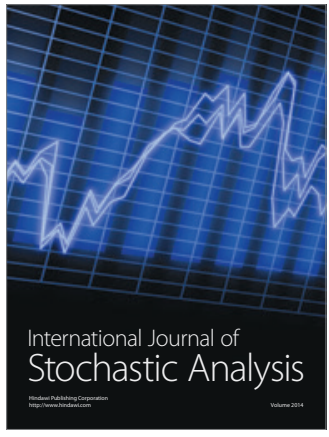

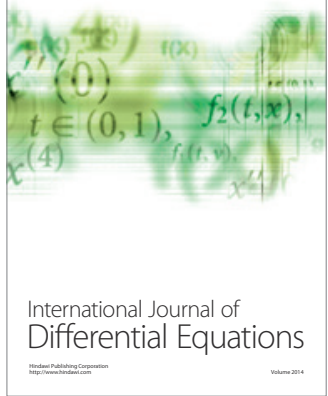
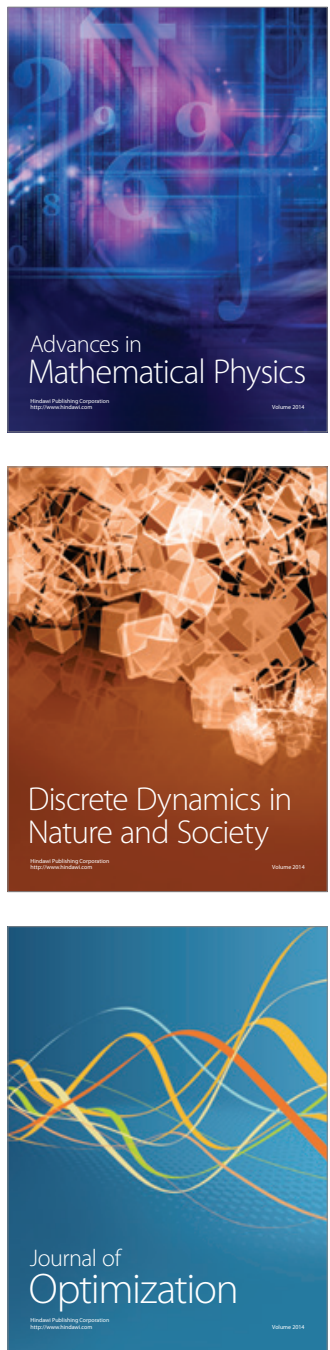